\title{
Nonlinear analysis of heart rhythm in preeclampsia: a route for translational clinical applications in neuroinflammation
}

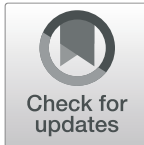

\author{
José Javier Reyes-Lagos ${ }^{1 *}$ (D) and Eric Alonso Abarca-Castro² ${ }^{2}$
}

\begin{abstract}
Preeclampsia is a pregnancy-specific condition which gets detected through hypertension and excessive protein excretion in urine. While preeclampsia used to be regarded as a self-limiting maternal condition which resolved with the delivery of the placenta, it is nowadays considered a complex and multifactorial disease that affects the offspring. Unfortunately, the etiology and pathophysiology of this multifaceted disorder remain elusive. Recent findings have confirmed that an altered maternal autonomic function may play a vital role in developing preeclampsia in conjunction with an imbalanced maternal immune system. Additionally, further evidence supports the crucial role of an exacerbated immune response driven by a non-infectious trigger during preeclampsia.

Therefore, as a sterile inflammation, the elucidation of the neuroinflammatory mechanisms of preeclampsia warrants obtaining relevant knowledge suitable for translational clinical applications.

Heart rate variability (HRV) is an affordable and non-invasive method for indirectly assessing the autonomic nervous system and the cholinergic anti-inflammatory pathway (CAP). Notably, the nonlinear analysis of HRV offers novel indexes to explore the neuroimmune interactions in diverse preclinical and clinical settings of inflammation. Given that the dynamics of HRV is nonlinear in health, we hypothesized that a neuroinflammatory condition in preeclampsia might be associated with changes in nonlinear features of maternal and fetal HRV. Thus, the present review aims to present evidence of the potential changes in maternal-fetal HRV associated with neuroinflammatory modifications in preeclamptic women. We considered that there is still a need for assessing the nonlinear features of maternal and fetal HRV as complementary biomarkers of inflammation in this population in future studies, being a potential route for translational clinical applications.
\end{abstract}

Keywords: Pregnancy, heart rate, Neuroimmunomodulation, Pre-eclampsia, Autonomic nervous system

\section{Background}

Preeclampsia is one of the leading causes of critical maternal and fetal mortality and morbidity. It is diagnosed by pregnancy-onset hypertension and proteinuria after 20 weeks of gestation [1]. Both preeclamptic women and their newborns are at higher risk of higher risk of

\footnotetext{
*Correspondence: jireyes|@uaemex.mx

${ }^{1}$ Autonomous University of the State of Mexico (UAEMex), School of Medicine, Toluca, State of Mexico, Mexico

Full list of author information is available at the end of the article
}

developing severe cardiovascular complications and metabolic syndromes later in life [2].

Preeclampsia's prevalence is estimated to be seven times higher in low-income countries compared to highincome countries [2]; thus, it is a public health problem and a significant cause of maternal death. The 2030 Agenda for Sustainable Development and the Millennium Development Goals have placed maternal wellbeing as a top priority concern, and the corresponding goal 3 is to decrease by 2030 the global maternal 
mortality ratio below 70 per 100,000 live births [3, 4]. In Mexico, the current maternal mortality ratio is estimated as 33 per 100,000 live births [5]. According to the World Health Organization (WHO), the most common direct causes of maternal mortality are preeclampsia/eclampsia, obstetric hemorrhage, and puerperal sepsis [6]. Authors suggest that a decrease in maternal mortality rate in low-income countries is associated with Human Development Index; thus, by increasing educational levels, income per capita, and life expectancy, a substantial reduction in maternal and child mortality rates is observed [7].

Conventionally, preeclampsia has been regarded as a self-limiting maternal pathological condition which gets completely resolved with the placenta's delivery. However, it is also considered a complex and multifactorial disease that may also have consequences for the offspring [8]. It is known that some characteristics of preeclampsia are: placental oxygen dysregulation, abnormal trophoblast invasion, overexpression of anti-angiogenic factors, anomalous maternal-fetal immune interactions [8], maternal autonomic dysfunction [9], and distress conditions [10].

Preeclampsia remains a particular disorder of pregnancy, with an incomplete understanding of its etiology [11]. Recent findings confirmed that an altered maternal autonomic function could play a key role in developing preeclampsia in conjunction with an imbalanced immune system $[12,13]$. It is noteworthy to mention that some clinical studies have demonstrated that this immune imbalance induced by preeclampsia promotes a chronic inflammatory state during pregnancy [14]. Additionally, authors have described preeclampsia as a multisystem disorder based on a cascade of immunopathological events originating from the placenta [15]. However, it is recognized that a single candidate mechanism does not explain preeclampsia's complex pathogenesis [15].

New disciplines such as neuroimmunology have emerged in order to provide a compelling integrative link between the immune system and nervous system. It recognizes that immune responses are present in the central and peripheral nervous systems during disease, considering the existence of a neuroimmune axis [16]. Some authors have proposed that novel psychophysiological indexes can assess the neurophysiological pathway responsible for adaptively regulating inflammatory processes in humans [17]. For example, the analysis of heartbeat fluctuations or heart rate variability (HRV) is a convenient, non-invasively, and economical method for quantifying the cardiac autonomic nervous system (ANS) [18]. In addition, the HRV has recently been considered an important "window" to understand better the neuroimmune system involved in inflammatory conditions $[19,20]$. Studies even reveal that several indexes of HRV seem to be related to inflammatory biomarkers in humans [21-24]. The exploration of HRV has provided a deeper understanding of the cholinergic anti-inflammatory pathway (CAP) [25-28], a neuroimmune mechanism that inhibits pro-inflammatory cytokine release via the vagus nerve [29].

According to the literature, linear approaches of HRV have been extensively studied and are not adequate to fully describe a complex system [30]. Particularly, nonlinear features of HRV are becoming increasingly important in present and future studies to comprehend complex biological systems in both health and disease [31]. Given that the healthy HRV time series shows nonlinear features, we hypothesized that a neuroinflammatory condition in preeclampsia might be associated with changes in nonlinear features of maternal and fetal HRV.

This review article aims to present evidence of the potential changes in HRV associated with neuroinflammatory modifications in preeclamptic women; we first describe the immune and neuroimmune profiles in preeclampsia, followed by linear and nonlinear HRV changes during preeclampsia. Finally, we discuss the nonlinear analysis of HRV as a novel tool for exploring inflammatory mechanisms in the maternal-fetal dyad during preeclampsia.

\section{Immune and neuroimmune profiles in preeclampsia}

According to some studies, the immune profile of women with preeclampsia shifts from a steady state of mild inflammation; from an equilibrium of both proinflammatory and anti-inflammatory mechanisms to a downregulated state characterized by increased inflammatory cytokines and effector immune cells with a concomitant decrease in anti-inflammatory factors and regulatory cells [32]. Other recent findings have documented an increased ratio of pro- to anti-inflammatory cytokines in preeclampsia, suggesting that the decreased levels of cytokines such as interleukin 4 (IL-4) and interleukin 10 (IL-10) accelerate the production of proinflammatory cytokines resulting in excessive inflammation [33]. Interestingly, further experimental studies showed that by infusing IL-10 to restore the immune system's balance, the blood pressure associated with placental ischemia in pregnant rats is reduced [13]. These results support a relevant role of the anti-inflammatory cytokines in preeclampsia. In line with such findings, novel studies report an association between the proinflammatory cytokine profile and lower plasma concentrations of soluble CD163 molecule and IL-10 of women with severe preeclampsia [34]. Authors have thus endorsed that assessing the cytokine profile of women with preeclampsia is convenient [35]. 
Preclinical evidence has indicated that interleukin 6 (IL-6) may play a role in mediating hypertension and reducing renal hemodynamics observed in uterine perfusion reductions in pregnant rats [36]. According to Conrad et al., elevated levels of tumor necrosis factoralpha (TNF- $\alpha$ ) and IL-6 may contribute to preeclampsia's putative endothelial dysfunction [37]. Novel evidence confirms that high levels of TNF- $\alpha$ have been associated with an increased risk of preeclampsia [38]. Additionally, new findings support a non-bacterial maternal immune response role in the development of preeclampsia and eclampsia [39]. For example, a sterile inflammation may be initiated by molecules in the host organism known as damage associated molecular patterns (DAMPs), Fig. 1. In preeclampsia, various DAMPs may be involved in this disorder's etiology or exacerbation [39].

Yang et al. [40] reported reduced vagus nerve function in preeclamptic women. Consequently, in these women, evidence suggests that diminished acetylcholine (ACh) synthesis may contribute to excessive inflammation and hypertension [41]. ACh serves as a neuromodulator in the central nervous system, affecting neuronal excitability, synaptic transmission, and plasticity [41]. Findings show that the mRNA expression levels of the alpha 7 nicotinic acetylcholine receptor ( $\alpha 7 \mathrm{nAChR})$ in preeclamptic women's monocytes were lower than control healthy women's monocytes. Thus, the authors concluded that the downregulation of $\alpha 7 \mathrm{nAChR}$ may be linked to the development of preeclampsia by boosting pro-inflammatory and decreasing anti-inflammatory cytokine release via the nuclear factor kappa $\beta(\mathrm{NF}-\mathrm{k} \beta)$ pathway [42]. Considering its ability to modulate antiinflammatory processes by reducing the expression of pro-inflammatory effectors and cytokines, $\alpha 7 \mathrm{nAChR}$ has received much attention in the last few decades [43]. Therefore, preeclampsia can be considered an altered neuroimmune condition in pregnant women, becoming a frontier topic for multiple disciplines, Fig. 1.

Novel findings suggest that the vagal-driven activation of the $\alpha 7 \mathrm{nAChR}$ attenuates preeclampsia-like symptoms, and this protective effect is likely result of the inhibition of inflammation via the NF- $\kappa \beta$ pathway [44].

McAllen et al., have provided compelling evidence in preclinical studies that indicates that splanchnic sympathetic outflow acts to suppress immune-mediated inflammation [45]. However, recent evidence shows that preeclampsia is not associated with elevated sympathetic reactivity evaluated by sympathetic nervous system activity [46]. Consistently, current evidence suggests that an autonomic dysfunction is highly prevalent in preeclamptic women [12].

There is still a lack of knowledge in how preeclampsia modifies the neuroimmune pathways; for example, some studies have reported an association among maternal immune activation, the manifestation of preeclampsia, and an altered neonatal neurodevelopment [47]. A possible pathway for this association involves the dysfunction of the microglial cells, which are the brain's immune cells [47]. In this sense, studies are necessary to

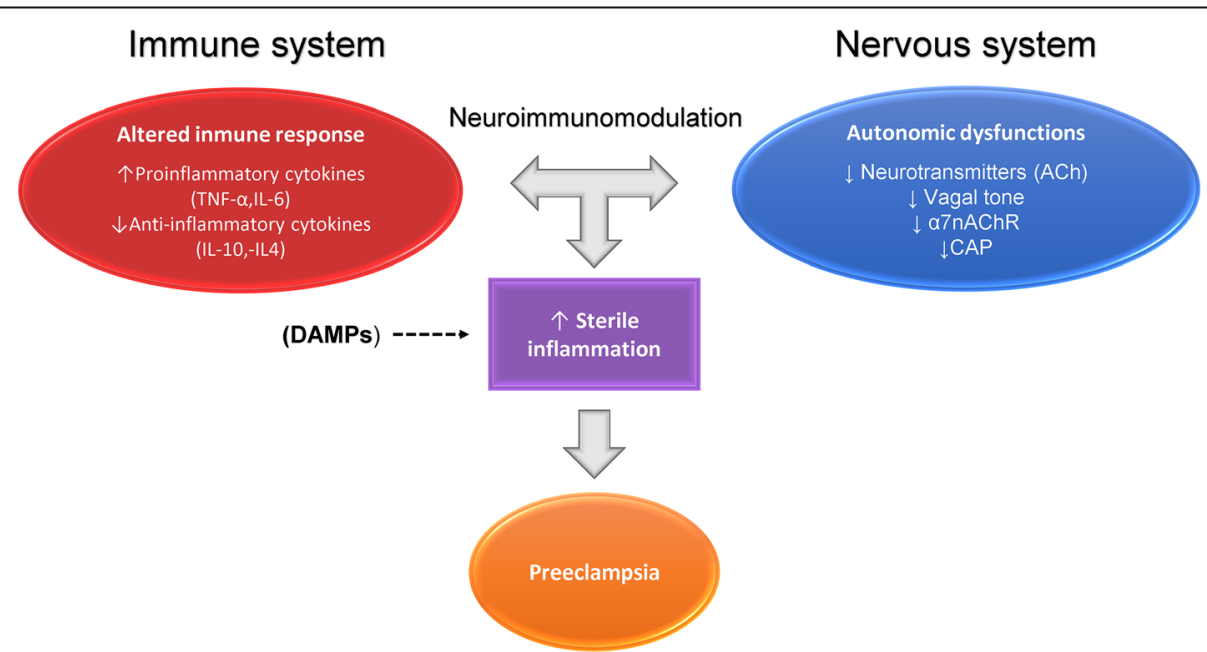

Fig. 1 Preeclampsia etiology or exacerbation may be mediated by an upregulated sterile inflammation, it may be initiated by molecules in the host organism known as damage associated molecular patterns (DAMPs). In addition to DAMPs, the upregulation of this sterile inflammation is produced by an altered immune response in conjunction with autonomic dysfunctions. Particularly, immune alterations are characterized by the release of pro-inflammatory cytokines such as tumor necrosis factor-alpha (TNF-a) and interleukin-6 (IL-6) and decrease of anti-inflammatory cytokines such as interleukin-4 (IL-4) and interleukin-10 (IL-10). Finally, autonomic dysfunctions may involve diminished acetylcholine (ACh) synthesis, lower vagal tone, downregulation of both alpha 7 nicotinic acetylcholine receptor (a7nAChR) and cholinergic anti-inflammatory pathway (CAP) 
provide more apprehensible knowledge about the neuroinflammatory mechanisms in preeclampsia. Biomedical research is pushing forward to developing potential non-invasive and fast diagnostic biomarkers for clinical translational applications.

\section{Linear and nonlinear HRV changes during preeclampsia}

Nonlinear HRV analysis is based on chaos theory, in which the heart rhythm generation, besides being sensitive to initial conditions and evolving very fast over time, is considered nonlinear [48, 49]. On the other hand, when using linear analysis techniques of HRV data, several assumptions must be made to ensure that the data is meaningfully interpreted. For example, the HRV data must be stationary, i.e., the mean and variance must be stable. However, it is recognized that the cardiac system is dynamic, nonlinear, and nonstationary [49]. Thus, linear methods of HRV may not account for all aspects of cardiac performance, especially the complex interactions between the control mechanisms that regulate heart function, due to assumptions and conditioning needed for linear HRV analysis [49]. In any case, both linear and nonlinear processing algorithms of HRV have provided useful computational tools for diagnosing a wide range of inflammatory conditions and pathologies [26-29]. According to a review of 2020, the most measurable nonlinear features of HRV are representation features (e.g., Poincaré plot representation, recurrence plot analysis, asymmetry); fractal (e.g., detrended fluctuation analysis, Hurst exponent); entropy or complexity-based features (e.g., Shannon entropy, sample entropy, multiscale entropy) and symbolic dynamics [50].

Evidence has also shown negative associations between linear HRV indexes such as the standard deviation of the normal-to-normal interval with TNF- $\alpha$ in heart failure patients, suggesting that the immune system's activation is related to autonomic imbalance [51]. More specifically, our previous research indicates that nonlinear features of HRV such as entropy-based methods, symbolic dynamics, and fractal methods have successfully characterized systemic acute inflammatory conditions such as the lipopolysaccharide (LPS) induced endotoxemia [5254] and low-risk human parturition at term [55].

Specifically, it is known that preeclampsia affects the cardiovascular health of both mother and offspring [56]. Studies also indicated that different hypertensive disorders such as chronic hypertension, preeclampsia, and pregnancy-induced hypertension (PIH) are different in $\mathrm{HRV}$, indicating that different regulatory mechanisms are involved [57]. In Mexican women, PIH's progression into preeclampsia has been appreciated in one of each four patients [35]; thus, the evaluation of HRV may be considered an additional biomarker for monitoring PIH patients who may develop preeclampsia. A recent review study indicates that, in general, a decrease in overall HRV is found in preeclampsia compared to normotensive pregnant controls [58]. Among different autonomic alterations in preeclampsia, a reduction in the autonomic vagal modulation and increased sympathetic autonomic modulation assessed by HRV analysis have been reported $[9,40]$.

Novel nonlinear measures have been introduced to describe HRV, which present the advantage of not being affected by nonstationary effects [59]. Table 1 summarizes the primary outcomes of clinical and preclinical studies of HRV and preeclampsia [9, 40, 57, 60-66]. Table 1 specifies the type of HRV measure (linear or nonlinear), and if the analysis was performed in fetal or maternal HRV data. Interestingly, only one $(1 / 10)$ of the consulted studies have evaluated nonlinear analysis of maternal or fetal HRV in women with preeclampsia.

\section{Nonlinear measures of HRV: a novel tool for the exploration of the CAP}

Nonlinear HRV measures or features have shown potential as biomarkers of internalizing psychopathology, often associating lower information-based complexity with internalizing psychopathology [67]. The relationships between physiological variability, interorgan communication, and disease suggest that monitoring complexity may reveal disease state; thus, decreased complexity would correspond with disease progression, and increased complexity (towards homeostasis) would correspond with recovery [68]. The complexity analysis of HRV data, which also quantifies nonlinear interactions among frequencies reflecting underlying ANS dynamics, represents a relevant topic in assessing neuroimmune disorders. However, this complexity also means that there is potentially a variety of information from a wide range of physiological systems embedded in the HRV, indicating an opportunity to utilize computational approaches to reveal the physiological significance of HRV.

Nonlinear measures of HRV have already allowed the discrimination of depressive patients from healthy subjects, consistently showing a significant decrease of HRV complexity in neuroimmune pathologies [69]. Mainly, multiscale entropy, a complexity measure of HRV, was more sensitive than current clinical markers for evaluating inflammation in a preclinical model of LPS-induced inflammation [70]. Authors suggest that multiscale entropy may prove a fruitful component of a bedside monitor to detect inflammatory insults.

According to the consulted literature, no clinical studies have been conducted to simultaneously evaluate the nonlinear features of HRV and multiple inflammation markers in women diagnosed with preeclampsia. However, results indicate that preeclamptic women reveal a reduced complexity by incrementing periodicity assessed 
Table 1 Study summaries of heart rate variability and preeclampsia

\begin{tabular}{|c|c|c|c|c|}
\hline Study & $\begin{array}{l}\text { Sample } \\
\text { size }\end{array}$ & $\begin{array}{l}\text { Monitoring } \\
\text { method }\end{array}$ & $\begin{array}{l}\text { HRV } \\
\text { measure }\end{array}$ & Conclusions \\
\hline $\begin{array}{l}\text { Clinical: } \\
\text { maternal } \\
\text { Chaswal et al. } \\
(2018)[9]\end{array}$ & 120 & HRV & Linear & $\begin{array}{l}\text { A reduction in autonomic vagal modulation and an increase in sympathetic autonomic } \\
\text { modulation in preeclampsia. }\end{array}$ \\
\hline $\begin{array}{l}\text { Clinical: } \\
\text { maternal } \\
\text { Yang et al. } \\
(2000)[40]\end{array}$ & 45 & HRV & Linear & $\begin{array}{l}\text { Preeclampsia is associated with a facilitation of sympathetic regulation and attenuation of } \\
\text { parasympathetic influence of heart rate. }\end{array}$ \\
\hline $\begin{array}{l}\text { Clinical: } \\
\text { maternal } \\
\text { Faber et al. } \\
\text { (2004 )[57] }\end{array}$ & 161 & HRV & $\begin{array}{l}\text { Linear } \\
\text { Nonlinear }\end{array}$ & Parameters of the HRV differ between various hypertensive pregnancy disorders. \\
\hline $\begin{array}{l}\text { Preclinical: fetal } \\
\text { Abuiessa et al. } \\
\text { (2020)[60] }\end{array}$ & 64 & HRV & Linear & $\begin{array}{l}\text { Preeclampsia accentuates endotoxic manifestations of hypotension, tachycardia, and cardiac } \\
\text { autonomic dysfunction in male offspring. }\end{array}$ \\
\hline $\begin{array}{l}\text { Clinical: } \\
\text { maternal } \\
\text { Speranza et al. } \\
(2019)[61]\end{array}$ & 60 & HRV & Linear & Autonomic activity increases during postpartum in preeclamptic women with severe features. \\
\hline $\begin{array}{l}\text { Clinical: } \\
\text { maternal and } \\
\text { fetal } \\
\text { Lakhno. } \\
\text { (2017) [62] }\end{array}$ & 106 & $\begin{array}{l}\text { HRV } \\
\text { Fetal CTG }\end{array}$ & Linear & The maternal and fetal hemodynamic coupling was reduced in preeclampsia. \\
\hline $\begin{array}{l}\text { Clinical: } \\
\text { maternal and } \\
\text { fetal } \\
\text { Hoyer et al. } \\
\text { (2017)[63] }\end{array}$ & 106 & HRV & Linear & $\begin{array}{l}\text { A sympathetic overactivity and the lack of vagal regulation lead to the loss of link between } \\
\text { maternal and fetal correlations of heart rate patterns in severe preeclampsia. }\end{array}$ \\
\hline $\begin{array}{l}\text { Clinical: } \\
\text { maternal } \\
\text { Hossen et al. } \\
(2017)[64]\end{array}$ & 40 & HRV & Linear & $\begin{array}{l}\text { During pregnancy and preeclampsia, parasympathetic activities are reduced, and sympathetic } \\
\text { activities are increased compared to healthy women. }\end{array}$ \\
\hline $\begin{array}{l}\text { Clinical: } \\
\text { maternal } \\
\text { Musa et al. } \\
(2016)[65]\end{array}$ & 120 & HRV & Linear & $\begin{array}{l}\text { A dominant cardiac sympathetic modulation on patients with preeclampsia was found, } \\
\text { probably secondary to parasympathetic withdrawal. }\end{array}$ \\
\hline $\begin{array}{l}\text { Clinical: fetal } \\
\text { Lakhno. } \\
\text { (2014)[66] }\end{array}$ & 160 & HRV & Linear & $\begin{array}{l}\text { A decreased fetal autonomic tone and predominance sympathetic regulation was marked in } \\
\text { preeclampsia. }\end{array}$ \\
\hline
\end{tabular}

HRV heart rate variability, CTG cardiotocography

HRV extracted from the maternal or fetal electrocardiogram

by multiscale asymmetry indexes of HRV [71]. The authors concluded that the mathematical indexes obtained with the nonlinear methods of HRV could differentiate between normal and preeclamptic pregnancies. At present, there is a clinical need to diagnose preeclampsia accurately and promptly, which usually progresses to an adverse fetal or maternal outcome.

The CAP activity can be monitored easily and noninvasively via the linear analysis of HRV data derived from either maternal or fetal electrocardiogram, Fig. 2. However, the linear analysis of HRV is not entirely appropriate to offer information about the complex dynamics of heartbeat fluctuations, and consequently, from the CAP activity. This is because the mechanisms involved in cardiovascular physiology interact with each other in a nonlinear way [72]. The activation of the CAP could rather be crucial for controlling preeclampsia symptoms. Besides, nonlinear methods of HRV not only present clinical relevance but also offer an improved interpretation of pathological conditions. Additionally, the main advantage of HRV signals is that they can be calculated in real-time and non-invasively, while all current biomarkers used in clinical practice are discrete and imply blood sample analyses which delay results.

The information derived from chaos theory, fractal mathematics, and the dynamic complexity of HRV has not yet been fully applied in the obstetrics field. It is a productive area for research in both healthy and 


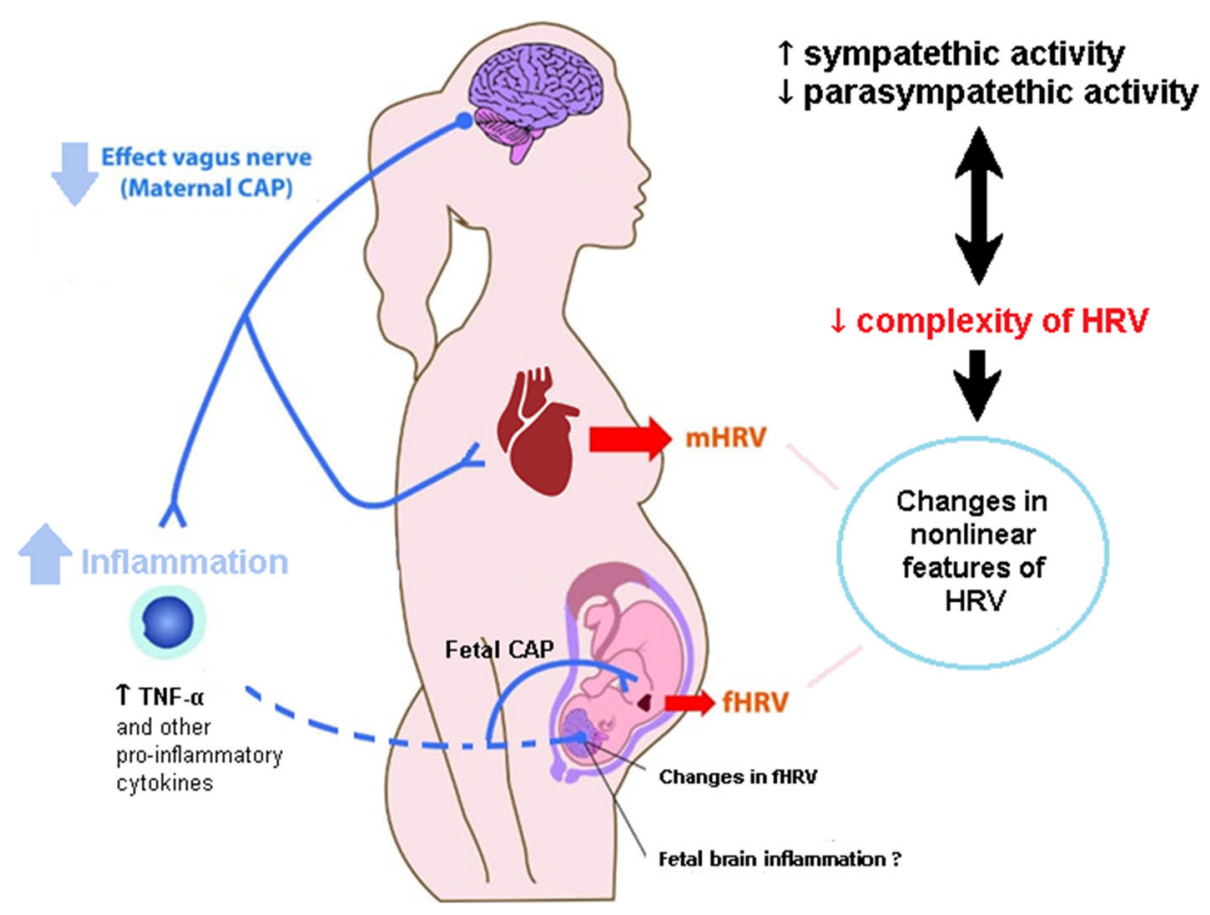

Fig. 2 Alterations in preeclampsia may involve increased cardiac sympathetic activity, decreased cardiac parasympathetic activity, and reduced complexity of heart rate fluctuations. These alterations may produce changes in nonlinear features of the maternal or fetal heart rate variability (mHRV and fHRV, respectively). A downregulated maternal cholinergic anti-inflammatory pathway (CAP) may result in a high pro-inflammatory state in the mother and fetus (increased levels of tumor necrosis factor-alpha [TNF-a], interleukin-6 [IL-6], and other pro-inflammatory cytokines). The assessment of nonlinear features of heart rate variability (HRV) is a potential tool for exploring the neuroinflammatory interactions in the maternal-fetal dyad

pathological scenarios. Also, the complex characterization of the HRV time series during preeclampsia has rarely been studied. Theoretically, the maternal and fetal nonlinear analysis of HRV offers unique opportunities to explore the neuroimmune interactions in the mother-child binomial.

\section{Conclusions}

Neuroinflammatory alterations in preeclamptic women may involve autonomic changes associated with a possible concomitant downregulated CAP and modifications in nonlinear features of HRV. We consider that the assessment of nonlinear measures of both maternal and fetal HRV during preeclampsia is a promising field for exploring the neuroinflammatory interactions in the maternal-fetal dyad and a route for potential translational clinical applications. The knowledge of this frontier topic promotes basic research and translational clinical applications for scientists worldwide who conduct research concerning inflammatory processes.

\section{Abbreviations}

a7nAChR: Alpha 7 nicotinic acetylcholine receptor; ACh: Acetylcholine: ANS: Autonomic nervous system; CAP: Cholinergic anti-inflammatory pathway; DAMPs: Damage associated molecular patterns; HRV: Heart rate variability; IL-4: Interleukin 4; IL-6: Interleukin 6; IL-10: Interleukin 10;
LPS: Lipopolysaccharide; NF-kß: Nuclear factor kappa $\beta$; PIH: Pregnancyinduced hypertension; TNF-a: Tumor necrosis factor-alpha; WHO: World Health Organization

\section{Acknowledgments}

J. Javier Reyes-Lagos thanks the Mexican Public Education Ministry (Secretaría de Educación Pública: SEP) for providing a fellowship (project number: 5116/2020-7841). Both authors thanks to Josué Hernández Delgado for his valuable suggestions.

\section{Authors' contributions}

$J J R-L$ wrote and revised the first draft of the manuscript, and EAA-C wrote and revised the draft manuscript. All authors have read and approved the final manuscript.

\section{Authors' information}

Affiliations.

JJR-L is full-time profesor at Facultad de Medicina, Universidad Autónoma del Estado de México (UAEMéx), Av Paseo Tollocan SN, Calle Jesús Carranza, Moderna de la Cruz, 50180, Toluca de Lerdo, Méx

EAA-C is doctoral graduated from the Centro de Investigaciones Multidisciplinarias en Educación (CIME), Universidad Autónoma del Estado de México, Corregidor Gutiérrez 209, Barrio de la Merced, 50080, Toluca de Lerdo, Méx.

\section{Funding}

No funding.

Availability of data and materials Not applicable. 


\section{Declarations}

\section{Ethics approval and consent to participate}

Not applicable.

\section{Consent for publication}

Not applicable.

\section{Competing interests}

The authors declare that they have no competing interests.

\section{Author details}

'Autonomous University of the State of Mexico (UAEMex), School of Medicine, Toluca, State of Mexico, Mexico. ${ }^{2}$ Autonomous University of the State of Mexico (UAEMex), Multidisciplinary Research Center in Education (CIME), Toluca, State of Mexico, Mexico.

\section{Received: 4 February 2021 Accepted: 25 September 2021}

Published online: 15 December 2021

\section{References}

1. Cornelius DC. Preeclampsia: from inflammation to immunoregulation. Clin Med Insights Blood Disord. 2018;11:1179545X17752325.

2. Malik A, Jee B, Gupta SK. Preeclampsia: disease biology and burden, its management strategies with reference to India. Pregnancy Hypertens. 2019; 15:23-31

3. Transforming our world: the 2030 agenda for sustainable development. In: William R, editor. A new era in global health: nursing and the United Nations 2030 agenda for sustainable development. New York: Springer Publishing Company; 2018. p. 519-67.

4. World Health Organization. Health in 2015: from MDGs to SDGs [internet]. Geneva: World Health Organization; 2015. https://316apps.who.int/iris/ha ndle/10665/200009. Accessed 4 Sep 2021

5. World Health Organization. Maternal mortality ratio (modeled estimate, pe 100,000 live births). Geneva: World Health Organization; 2015. https://data. worldbank.org/indicator/sh.sta.mmrt. Accessed 30 Oct 2019

6. Singla A, Rajaram S, Mehta S, Radhakrishnan G. A ten year audit of maternal mortality: millennium development still a distant goal. Indian J Community Med. 2017;42:102-6.

7. Alimohamadi Y, Khodamoradi F, Khoramdad M, Shahbaz M, Esmaeilzadeh F. Human development index, maternal mortality rate and under 5 years mortality rate in west and south Asian countries, 1980-2010: an ecological study. East Mediterr Health J. 2019:25:189-96.

8. Pennington KA, Schlitt JM, Jackson DL, Schulz LC, Schust DJ. Preeclampsia: multiple approaches for a multifactorial disease. Dis Model Mech. 2012;5:918.

9. Chaswal M, Kapoor R, Batra A, Verma S, Yadav BS. Heart rate variability and cardiovascular reflex tests for assessment of autonomic functions in preeclampsia. Int J Hypertens. 2018;2018:8163824.

10. Vianna P, Bauer ME, Dornfeld D, Chies JA. Distress conditions during pregnancy may lead to pre-eclampsia by increasing cortisol levels and altering lymphocyte sensitivity to glucocorticoids. Med Hypotheses. 2011;77: 188-91.

11. George EM. New approaches for managing preeclampsia: clues from clinical and basic research. Clin Ther. 2014;36:1873-81.

12. Yousif D, Bellos I, Penzlin Al, Hijazi MM, Illigens BM, Pinter A, et al. Autonomic dysfunction in preeclampsia: a systematic review. Front Neurol. 2019:10:816

13. Harmon AC, Cornelius DC, Amaral LM, Faulkner JL, Cunningham MW Jr, Wallace $\mathrm{K}$, et al. The role of inflammation in the pathology of preeclampsia. Clin Sci (Lond). 2016;130:409-19.

14. Ma Y, Ye Y, Zhang J, Ruan CC, Gao PJ. Immune imbalance is associated with the development of preeclampsia. Medicine (Baltimore). 2019;98:e15080.

15. Matthiesen L, Berg G, Ernerudh J, Ekerfelt C, Jonsson Y, Sharma S. Immunology of preeclampsia. Chem Immunol Allergy. 2005;89:49-61.

16. Nutma E, Willison H, Martino G, Amor S. Neuroimmunology: the past, present and future. Clin Exp Immunol. 2019;197:278-93.

17. Williams DP, Koenig J, Carnevali L, Sgoifo A, Jarczok MN, Sternberg EM, et al. Heart rate variability and inflammation: a meta-analysis of human studies. Brain Behav Immun. 2019;80:219-26.
18. Task Force of the European Society of Cardiology and the North American Society of Pacing and Electrophysiology. Heart rate variability: standards of measurement, physiological interpretation, and clinical use. Eur Heart J. 1996:17:354-81.

19. Huston JM, Tracey KJ. The pulse of inflammation: heart rate variability, the cholinergic anti-inflammatory pathway and implications for therapy. J Intern Med. 2011;269:45-53.

20. Barizien N, Le Guen M, Russel S, Touche P, Huang F, Vallée A. Clinical characterization of dysautonomia in long COVID-19 patients. Sci Rep. 2021; 11:14042.

21. Papaioannou V, Pneumatikos I, Maglaveras N. Association of heart rate variability and inflammatory response in patients with cardiovascular diseases: current strengths and limitations. Front Physiol. 2013;4:174.

22. Carney RM, Freedland KE, Stein PK, Miller GE, Steinmeyer B, Rich MW, et al. Heart rate variability and markers of inflammation and coagulation in depressed patients with coronary heart disease. J Psychosom Res. 2007;62: 463-7.

23. Papaioannou V, Pnevmatikos I. Heart rate variability: a potential tool for monitoring immunomodulatory effects of parenteral fish oil feeding in patients with sepsis. Nutr Metab Insights. 2019;12:1178638819847486.

24. Aeschbacher S, Schoen T, Dörig L, Kreuzmann R, Neuhauser C, SchmidtTrucksäss A, et al. Heart rate, heart rate variability and inflammatory biomarkers among young and healthy adults. Ann Med. 2017:49:32-41.

25. Tonhajzerova I, Mokra D, Visnovcova Z. Vagal function indexed by respiratory sinus arrhythmia and cholinergic anti-inflammatory pathway. Respir Physiol Neurobiol. 2013;187:78-81.

26. Eftekhari $G$, Ahmadi Soleimani SM, Mani AR. Heart rate variability, vagal activity and the pulse of inflammation. J Intern Med. 2013;274:490-1.

27. Cooper TM, McKinley PS, Seeman TE, Choo TH, Lee S, Sloan RP. Heart rate variability predicts levels of inflammatory markers: evidence for the vagal anti-inflammatory pathway. Brain Behav Immun. 2015;49:94-100.

28. Garzoni L, Faure C, Frasch MG. Fetal cholinergic anti-inflammatory pathway and necrotizing enterocolitis: the brain-gut connection begins in utero. Front Integr Neurosci. 2013;7:57.

29. Mazloom R, Eftekhari G, Rahimi-Balaei M, Khori V, Hajizadeh S, Dehpour AR, et al. The role of a7 nicotinic acetylcholine receptor in modulation of heart rate dynamics in endotoxemic rats. PLoS One. 2013;8:e82251.

30. Voss A, Schroeder R, Vallverdú M, Schulz S, Cygankiewicz I, Vázquez R, et al. Short-term vs long-term heart rate variability in ischemic cardiomyopathy risk stratification. Front Physiol. 2013:4:364.

31. Spasić SZ, Kesić S. Editorial: nonlinearity in living systems: theoretical and practical perspectives on metrics of physiological signal complexity. Front Physiol. 2019;10:298.

32. Cornelius DC, Cottrell J, Amaral LM, LaMarca B. Inflammatory mediators: a causal link to hypertension during preeclampsia. Br J Pharmacol. 2019;176: 1914-21.

33. Aggarwal $R$, Jain AK, Mittal P, Kohli M, Jawanjal P, Rath G. Association of pro- and anti-inflammatory cytokines in preeclampsia. J Clin Lab Anal. 2019; 33:e22834.

34. Nunes PR, Romão-Veiga M, Peraçoli JC, Araujo Costa RA, de Oliveira LG, Borges VT, et al. Downregulation of CD163 in monocytes and its soluble form in the plasma is associated with a pro-inflammatory profile in pregnant women with preeclampsia. Immunol Res. 2019;67: 194-201.

35. Daneva AM, Hadži-Lega M, Stefanovic M. Correlation of the system of cytokines in moderate and severe preeclampsia. Clin Exp Obstet Gynecol. 2016;43:220-4.

36. Gadonski G, LaMarca BB, Sullivan E, Bennett W, Chandler D, Granger JP. Hypertension produced by reductions in uterine perfusion in the pregnant rat: role of interleukin 6. Hypertension. 2006:48:711-6.

37. Conrad KP, Miles TM, Benyo DF. Circulating levels of immunoreactive cytokines in women with preeclampsia. Am J Reprod Immunol. 1998:40: 102-11.

38. Žák P, Souček M. Correlation of tumor necrosis factor alpha, interleukin 6 and interleukin 10 with blood pressure, risk of preeclampsia and low birth weight in gestational diabetes. Physiol Res. 2019;68:395-408.

39. Fodor P, White B, Khan R. Inflammation: the role of ATP in pre-eclampsia. Microcirculation. 2020;27:e12585.

40. Yang CC, Chao TC, Kuo TB, Yin CS, Chen HI. Preeclamptic pregnancy is associated with increased sympathetic and decreased parasympathetic control of HR. Am J Physiol Heart Circ Physiol. 2000;278:H1269-73. 
41. Perucci LO, Corrêa MD, Dusse LM, Gomes KB, Sousa LP. Resolution of inflammation pathways in preeclampsia: a narrative review. Immunol Res. 2017;65:774-89.

42. Xu H, Shi Q, Mo Y, Wu L, Gu J, Xu Y. Downregulation of a7 nicotinic acetylcholine receptors in peripheral blood monocytes is associated with enhanced inflammation in preeclampsia. BMC Pregnancy Childbirth. 2019; 19:188.

43. Piovesana R, Salazar Intriago MS, Dini L, Tata AM. Cholinergic modulation of neuroinflammation: focus on a7 nicotinic receptor. Int J Mol Sci. 2021;22: 4912.

44. Liu Y, Yang J, Bao J, Li X, Ye A, Zhang G, et al. Activation of the cholinergic anti-inflammatory pathway by nicotine ameliorates lipopolysaccharideinduced preeclampsia-like symptoms in pregnant rats. Placenta. 2017;49:2332.

45. Martelli D, Farmer DG, McKinley MJ, Yao ST, McAllen RM. Anti-inflammatory reflex action of splanchnic sympathetic nerves is distributed across abdominal organs. Am J Phys Regul Integr Comp Phys. 2019;316:R235-42.

46. Reyes LM, Usselman CW, Khurana R, Chari RS, Stickland MK, Davidge ST, et al. Preeclampsia is not associated with elevated muscle sympathetic reactivity. J Appl Physiol (1985). 2021;130:139-48.

47. Prins JR, Eskandar S, Eggen BJL, Scherjon SA. Microglia, the missing link in maternal immune activation and fetal neurodevelopment; and a possible link in preeclampsia and disturbed neurodevelopment? J Reprod Immunol. 2018;126:18-22

48. Canga L, Navarro A, Bolea J, Remartínez JM, Laguna P, Bailón R. Non-linear analysis of heart rate variability and its application to predict hypotension during spinal anesthesia for cesarean delivery. Comput Cardiol (2010). 2012; 39:413-6.

49. Schumacher A. Linear and nonlinear approaches to the analysis of R-R interval variability. Biol Res Nurs. 2004;5:211-21.

50. Henriques T, Ribeiro M, Teixeira A, Castro L, Antunes L, Costa-Santos C. Nonlinear methods most applied to heart-rate time series: a review. Entropy (Basel). 2020;22:309.

51. Nikolic VN, Jevtovic-Stoimenov T, Stokanovic D, Milovanovic M, VelickovicRadovanovic R, Pesic S, et al. An inverse correlation between TNF alpha serum levels and heart rate variability in patients with heart failure. J Cardiol. 2013;62:37-43

52. Reyes-Lagos JJ, Ledesma-Ramírez Cl, Hadamitzky M, Peña-Castillo MÁ Echeverría JC, Lückemann $L$, et al. Symbolic analysis of heart rate fluctuations identifies cardiac autonomic modifications during LPS-induced endotoxemia. Auton Neurosci. 2019;221:102577.

53. Elorza-Ávila AR, Reyes-Lagos JJ, Hadamitzky M, Peña-Castillo MÁ, Echeverría JC, Ortiz-Pedroza MD, et al. Oxytocin's role on the cardiorespiratory activity of endotoxemic rats. Respir Physiol Neurobiol. 2017;236:19-22.

54. Reyes-Lagos JJ, Hadamitzky M, Peña-Castillo MÁ, Echeverría JC, Bösche K, Lückemann L, et al. Exogenous oxytocin reduces signs of sickness behavior and modifies heart rate fluctuations of endotoxemic rats. Physiol Behav. 2016;165:223-30

55. Reyes-Lagos JJ, Ledesma-Ramírez Cl, Pliego-Carrillo AC, Peña-Castillo MÁ Echeverría JC, Becerril-Villanueva E, et al. Neuroautonomic activity evidences parturition as a complex and integrated neuro-immune-endocrine process. Ann N Y Acad Sci. 2019;1437:22-30.

56. Davis EF, Newton L, Lewandowski AJ, Lazdam M, Kelly BA, Kyriakou T, et al, Pre-eclampsia and offspring cardiovascular health: mechanistic insights from experimental studies. Clin Sci (Lond). 2012;123:53-72

57. Faber R, Baumert M, Stepan H, Wessel N, Voss A, Walther T. Baroreflex sensitivity, heart rate, and blood pressure variability in hypertensive pregnancy disorders. J Hum Hypertens. 2004;18:707-12.

58. Moors S, Staaks KJ, Westerhuis ME, Dekker LR, Verdurmen KM, Oei SG, et al. Heart rate variability in hypertensive pregnancy disorders: a systematic review. Pregnancy Hypertens. 2020;20:56-68.

59. Francesco B, Maria Grazia B, Emanuele G, Valentina F, Sara C, Chiara F, et al. Linear and nonlinear heart rate variability indexes in clinical practice. Comput Math Methods Med. 2012;2012:219080.

60. Abuiessa SA, Wedn AM, El-Gowilly SM, Helmy MM, El-Mas MM. Preeclamptic fetal programming alters neuroinflammatory and cardiovascular consequences of endotoxemia in sex-specific manners. J Pharmacol Exp Ther. 2020;373:325-36.

61. Speranza RJ, Rincon M, Greiner KS, Brookfield K, Togioka B, Burwick RM. 1023: autonomic regulation of maternal heart rate variability in preeclampsia. Am J Obstet Gynecol. 2019;220(1 Suppl):S657.
62. Lakhno I. Autonomic imbalance captures maternal and fetal circulatory response to pre-eclampsia. Clin Hypertens. 2017;23:5.

63. Hoyer D, Żebrowski J, Cysarz D, Gonçalves H, Pytlik A, Amorim-Costa C, et al. Monitoring fetal maturation-objectives, techniques and indices of autonomic function. Physiol Meas. 2017;38:R61-88.

64. Hossen A, Barhoum A, Jaju D, Gowri V, Al-Hashmi K, Hassan MO, et al. Identification of patients with preeclampsia from normal subjects using wavelet-based spectral analysis of heart rate variability. Technol Health Care. 2017;25:641-9.

65. Musa SM, Adam I, Lutfi MF. Heart rate variability and autonomic modulations in preeclampsia. PLoS One. 2016;11:e0152704.

66. Lakhno I. The impact of preeclampsia on fetal ECG morphology and heart rate variability. Arch Perinat Med. 2014;20:7-10.

67. Fiskum C, Andersen TG, Bornas X, Aslaksen PM, Flaten MA, Jacobsen K. Nonlinear heart rate variability as a discriminator of internalizing psychopathology and negative affect in children with internalizing problems and healthy controls. Front Physiol. 2018;9:561.

68. Scheff JD, Calvano SE, Androulakis IP. Multiscale equation-based models: insights for inflammation and physiological variability. In: Vodovotz Y, An G, editors. Complex systems and computational biology approaches to acute inflammation. New York: Springer; 2013. p. 125-41.

69. Leistedt SJ, Linkowski P, Lanquart JP, Mietus JE, Davis RB, Goldberger AL, et al. Decreased neuroautonomic complexity in men during an acute major depressive episode: analysis of heart rate dynamics. Transl Psychiatry. 2011;1: e27.

70. Herlitz GN, Arlow RL, Cheung NH, Coyle SM, Griffel B, Macor MA, et al. Physiologic variability at the verge of systemic inflammation: multiscale entropy of heart rate variability is affected by very low doses of endotoxin. Shock. 2015;43:133-9.

71. Tejera E, Rodrigues Al, Areias MJ, Rebelo I, Nieto-Villar JM. Network centrality and multiscale transition asymmetry in the heart rate variability analysis of normal and preeclamptic pregnancies. Commun Nonlinear Sci Numer Simul. 2011;16:1589-96.

72. de Godoy MF. Nonlinear analysis of heart rate variability: a comprehensive review. J Cardiol Ther. 2016:3:528-33.

\section{Publisher's Note}

Springer Nature remains neutral with regard to jurisdictional claims in published maps and institutional affiliations.

Ready to submit your research? Choose BMC and benefit from:

- fast, convenient online submission

- thorough peer review by experienced researchers in your field

- rapid publication on acceptance

- support for research data, including large and complex data types

- gold Open Access which fosters wider collaboration and increased citations

- maximum visibility for your research: over $100 \mathrm{M}$ website views per year

At $\mathrm{BMC}$, research is always in progress.

Learn more biomedcentral.com/submissions 